\title{
Occupational Exposure to pesticides and spontaneous abortion among female pistachio farmers: a case-control study
}

\author{
Vazirinejad R, $\mathrm{PhD}^{1}$, Jamalizadeh A, $\mathrm{MD}^{2}$, Tajik $\mathrm{S}, \mathrm{MS}^{3}$, Shamsizadeh A, $\mathrm{PhD}^{4^{*}}$ \\ 1- Associate Prof., Social Determinants of Health Research Centre, Medical School, Rafsanjan University of Medical \\ Sciences, Rafsanjan, Iran. 2- Physician, Social Medicine Dept., Medical School, Rafsanjan University of Medical \\ Sciences, Rafsanjan, Iran. 3- Medical Students, Medical School, Rafsanjan University of Medical Sciences, Rafsanjan, \\ Iran. 4- Assistant Prof., Physiology-Pharmacology research centre, Rafsanjan University of Medical Sciences, Rafsanjan, \\ Iran
}

Abstract

Received: May 2012, Accepted: September 2012

Background: The majoritiy of abortion risk factors has been classified as environmental and vary from one place to another. This study aimed to explore the relationship between exposure to pesticides and spontaneous abortion among female pistachio farmers in Rafsanjan, Iran.

Materials and Methods: In this case-control study, 50 women with spontaneous abortion and 50 women without this history who were matched based on some factors were recruited. Cases and controls were recruited through the list of all pregnant women who were registered in the rural health centers of the county. A written consent form was taken. Dependent and independent variables were experiencing spontaneous abortion and had been exposed to pistachio farms pesticides, respectively. Data were analyzed using descriptive statistics. Odds ratio was also calculated to measure the level of risk for spontaneous abortion after exposing to pistachio pesticides and $95 \%$ confidence interval was reported.

Results: About $72 \%$ and $22 \%$ of mothers with and without spontaneous abortion had experienced working in pistachio farms during their pregnancy, respectively. There was a significant level of risk for mothers who had worked in pistachio farms (during their pregnancy) to experience spontaneous abortion compared to those mothers who did not (Odds Ratio=9.1, 95\% CI=3.7-22.6). Odds ratio showed an increasing risk of spontaneous abortion among those who helped with spraying pesticides in pistachio farms compared to those mothers who did not $(\mathrm{OR}=9.3$, 95\% CI=2.0-43.7).

Conclusion: Exposure to pesticides has been a major risk for causing spontaneous abortion among pregnant pistachio farmers in the area of this research. Further investigations are recommended.

Key words: Spontaneous Abortion, Pregnancy, Pesticides, Pistachio

\section{Introduction}

Pesticides are mainly utilized in agriculture for crop protection. Pesticides are also applied in homes and gardens. More than 140,000 tones of pesticides are used annually in the European Union for agricultural purposes only [1]. A pesticide is "any substance or mixture of substances intended for preventing, destroying or controlling any pest" [2]. Pesticides may differ according to their chemical structure. Pesticides are suspected for causing short-term adverse health effects as well as for a wide range of

\footnotetext{
* Corresponding Author: Ali Shamsizadeh, Physiology-Pharmacology research centre, Rafsanjan University of Medical Sciences, Rafsanjan, Iran. E-mail: ashamsi@rums.ac.ir or alishamsy@gmail.com
} 
chronic effects. Acute health effects include stinging eyes, rashes, blisters, blindness, nausea, dizziness, diarrhea and death [3, 4]. Chronic effects, which can occur months or years after the exposure, include cancers, neurological and developmental toxicity, immunotoxicity, genotoxicity, respiratory effects and disruption of the endocrine system. Pesticides may affect not only the exposed individual but also subsequent generations [5-8]. There has been a rising concern about the adverse effects of pesticides on human reproduction, ranging from subfertility to abortion and malformations [9-11].

Abortion could be committed due to some medical reasons. However, some other sorts of abortion might happen as a result of unpredicted factors. These factors result in spontaneous abortion. Many risk factors have been known to cause spontaneous abortion among pregnant women. The big majorities of these factors are classified as environmental factors and vary from one place to another. Sometimes some sorts of man-made products can cause abortion, however, these products might be medications such as thalidomide [12]. The effect of exposure to X-Ray or other types of radiations on abortion among pregnant women has also been well documented.

Occupational and environmental exposures to farming [13-16] and pesticides [15, 17, 18, 19], have been associated with pathological disorders such as tumors. Some pesticides contain alkylureas or amines that metabolize to nitroso compounds, which have been associated with neurogenic tumors [19, 20]. A broad range of these products have been identified so far and most of them would harm when are, in particular, used in an abnormal range. Huge amounts of pesticides are being used in pistachio farms by both male and female farmers annually.
This study aimed to explore the relationship between exposure to pesticides and spontaneous abortion among female pistachio farmers in Rafsanjan, Iran.

\section{Material and Methods}

In this case-control study, 50 women with spontaneous abortion and 50 women without this history (giving natural birth) who were matched to the case group based on some factors such as age, the number of pregnancy, social class, place of living, educational status, and the exposure to trauma and X-ray during pregnancy were recruited. Respondents in both case and control groups were invited to three rural health centres located in Southeast area of Rafsanjan, Iran. For selecting cases, all eligible female farmers, who were registered as experiencing spontaneous abortion in the last 12 months, in the three health centres were listed, based on the date of their abortion. There were 71 women in the list, and almost 45 days had passed since latest spontaneous abortion. In other words, women in the case group had had a spontaneous abortion in the last 12 months and their pregnancy was terminated by unwanted abortions. The first 50 women experiencing spontaneous abortion, who were eligible according to inclusion criteria of the study were invited. They received details about the method and the objectives of the study. A written consent form was taken from respondents who were willing to help with the study. The method of the study was approved by the ethics committee of the university. Women in the control group were invited from the list of all women who had a natural duration of pregnancy and gave births normality, without experiencing abortion in the same period of time as women in the case group (in the last twelve months). 
Inclusion criteria of the study included; ages between 18 and 40 years, receiving no medication during pregnancy, and no history of disease, trauma, smoking and/or exposure to X-ray during pregnancy. Further to these criteria, cases who had experienced spontaneous abortion during the last 12 months were included.

Dependent and independent variables in our analytical study were experiencing spontaneous abortion and exposure to pistachio farms' pesticides, respectively. Data were collected by trained experts using a study checklist in interview sessions. The study checklist included items about the factors listed above including inclusion criteria items and some more demographic factors such as the number of pregnancy, social class, the place of living (city/village), educational status and the history of abortion and its date (months, day, time). Respondents were interviewed in the health centers. For the purpose of measuring social class, annual income of the respondent's family were recorded and divided into 12 months. Monthly family income less than 4000,000 Rls, between 4000,000 and 10,000,000 Rls and more than $10,000,000 \mathrm{Rls}$ were considered as low, moderate and high social class, respectively.

In order to assess the history of exposure to pesticides, there were few items on the checklist including; "were you living in or near a pistachio farm during pregnancy?", "did you work in the pistachio farms to spray pesticide during pregnancy?", "how often did you work in the pistachio farms to spray pesticides during pregnancy (per week)?", "how much time, on average (minutes) did you spend in the pistachio farms to spray pesticide per each session, during pregnancy?".

Positive answer to the first two questions showed exposure to the pesticides. Data were analyzed in SPSS and results were reported using descriptive statistics methods such as tables, charts and numerical indices. Parametric tests (such as t-test) and nonparametric tests (such as Chi-square) were used to compare groups where appropriate. Odds ratio (OR) was also calculated to measure the level of risk for spontaneous abortion after exposing to pistachio pesticides and $95 \%$ confidence interval was reported.

\section{Results}

Mean age of respondents in the two groups of case (a group of mothers with the history of spontaneous abortion) and control (a group of mothers without the history of spontaneous abortion) were $30.8 \pm 5.8$ and $28.9 \pm 5.2$ years, respectively. There was no significant difference of age between the two groups. Distribution of respondents in the two groups of case and control based on some demographic variables is presented in table 1.

As it is presented in the table, there was not any significant differences between the two groups of case and control based on the number of pregnancy, social class, the place of living, family job, educational status, and the exposure to trauma and X-ray during pregnancy. There was no smoker among our respondents. As it is illustrated in table 2, 98\% of mothers with spontaneous abortion were living inside the pistachio farms, whereas $88 \%$ of mothers in the other group were living inside pistachio farms during their pregnancy. Eight percent of mothers in the case group had a history of experiencing spontaneous abortion in their family. There was not spontaneous abortion reported among the family of mothers in control group. 
Table 1: Distribution of respondents in the two groups of case and control based on some demographic variables

\begin{tabular}{|c|c|c|c|c|c|c|}
\hline \multirow{3}{*}{ Demographic variables } & \multicolumn{4}{|c|}{ Spontaneous abortion (groups) } & \multirow{2}{*}{\multicolumn{2}{|c|}{ Total }} \\
\hline & \multicolumn{2}{|c|}{ Yes (case) } & \multicolumn{2}{|c|}{ No (control) } & & \\
\hline & $\mathrm{N}$ & $\%$ & $\mathrm{~N}$ & $\%$ & $\mathrm{~N}$ & $\%$ \\
\hline \multicolumn{7}{|l|}{ The No. of pregnancies } \\
\hline-1 & 33 & 66 & 29 & 58 & 62 & 62 \\
\hline$-1-2$ & 11 & 22 & 15 & 30 & 26 & 26 \\
\hline$->2$ & 6 & 12 & 6 & 12 & 12 & 12 \\
\hline \multicolumn{7}{|l|}{ Educational status } \\
\hline - illiteracy & 1 & 2 & 0 & 0 & 1 & 1 \\
\hline - primary/secondary & 13 & 26 & 14 & 28 & 27 & 27 \\
\hline - high school/diploma & 29 & 58 & 24 & 48 & 53 & 53 \\
\hline - higher & 7 & 14 & 12 & 24 & 19 & 19 \\
\hline \multicolumn{7}{|l|}{ Family job } \\
\hline - labor & 36 & 72 & 34 & 68 & 70 & 70 \\
\hline - farmer & 12 & 24 & 16 & 32 & 28 & 28 \\
\hline - other & 2 & 4 & 0 & 0 & 2 & 2 \\
\hline \multicolumn{7}{|l|}{ Living place } \\
\hline - city & 47 & 94 & 49 & 98 & 96 & 96 \\
\hline - village & 3 & 6 & 1 & 2 & 4 & 4 \\
\hline \multicolumn{7}{|l|}{ Trauma } \\
\hline - Yes & 1 & 2 & 0 & 0 & 1 & 1 \\
\hline - No & 49 & 98 & 50 & 100 & 99 & 99 \\
\hline \multicolumn{7}{|l|}{ X-Ray } \\
\hline - Yes & 0 & 0 & 1 & 2 & 1 & 1 \\
\hline - No & 50 & 100 & 49 & 98 & 99 & 99 \\
\hline \multicolumn{7}{|l|}{ Social class } \\
\hline - Low & 17 & 34 & 16 & 32 & 33 & 33 \\
\hline - Moderate & 27 & 54 & 28 & 56 & 55 & 55 \\
\hline - High & 6 & 12 & 6 & 12 & 12 & 12 \\
\hline
\end{tabular}

In order to measure the exposure of respondents to pesticides used in pistachio farms, items were asked about their cooperation in farming activities as well as their cooperation in spraying pesticides during their pregnancy. Living place of mothers during their pregnancy was also recorded. The distance between the place of respondents residence during the pregnancy and pistachio farms was also recorded for women in the two groups of case and control. The average of this distance for the two groups of case and control were $1.7 \pm 0.5$ and $2.5 \pm 1.5 \mathrm{~km}$, respectively. The results of independent t-test showed that the distance between the living place of mothers with spontaneous abortion and pistachio farms was significantly shorter than this distance for mothers without the history of abortion $(\mathrm{t}=3.3, \mathrm{df}=98, \mathrm{p}<0.001)$. The level of risk for experiencing spontaneous abortion among mothers who were living inside pistachio farms was 6.7 times higher (OR= $6.7,95 \% \mathrm{CI}=1-57.7)$ than this risk among those mothers who were living outside pistachio farms during their pregnancy (table2).

The results showed that $72 \%$ of mothers with spontaneous abortion experienced working in pistachio farms during their pregnancy. This proportion for mothers in the control group (without spontaneous abortion) was 22\% (table 2). There was a significant level of risk for mothers who worked in pistachio farms (during their pregnancy) to experience spontaneous abortion compared to mothers who did not $(\mathrm{OR}=9.1,95 \% \mathrm{CI}=3.7-22.6)$ (table3). 
Table 2: Distribution of mothers in the two groups of case and control based on some effective variables

\begin{tabular}{|c|c|c|c|c|c|c|}
\hline \multirow{3}{*}{ Effective variables } & \multicolumn{4}{|c|}{ groups } & \multirow{2}{*}{\multicolumn{2}{|c|}{ Total }} \\
\hline & \multicolumn{2}{|c|}{ case } & \multicolumn{2}{|c|}{ control } & & \\
\hline & $\mathrm{N}$ & $\%$ & $\mathrm{~N}$ & $\%$ & $\mathrm{~N}$ & $\%$ \\
\hline $\begin{array}{l}\text { Living place During pregnancy } \\
\text { - Outside pistachio farms } \\
\text { - Inside pistachio farms }\end{array}$ & $\begin{array}{c}1 \\
49\end{array}$ & $\begin{array}{c}2 \\
98\end{array}$ & $\begin{array}{c}6 \\
44\end{array}$ & $\begin{array}{l}12 \\
88\end{array}$ & $\begin{array}{c}7 \\
93\end{array}$ & $\begin{array}{c}7 \\
93\end{array}$ \\
\hline $\begin{array}{l}\text { History of abortion in family } \\
\text { - No } \\
\text { - Yes }\end{array}$ & $\begin{array}{c}46 \\
4\end{array}$ & $\begin{array}{c}92 \\
8\end{array}$ & $\begin{array}{c}50 \\
0\end{array}$ & $\begin{array}{c}100 \\
0\end{array}$ & $\begin{array}{c}96 \\
4\end{array}$ & $\begin{array}{c}96 \\
4\end{array}$ \\
\hline $\begin{array}{l}\text { Farming (working in pistachio } \\
\text { farms) } \\
\text { - No } \\
\text { - Yes }\end{array}$ & $\begin{array}{l}14 \\
36\end{array}$ & $\begin{array}{l}28 \\
72\end{array}$ & $\begin{array}{l}39 \\
11\end{array}$ & $\begin{array}{l}78 \\
22\end{array}$ & $\begin{array}{l}53 \\
47\end{array}$ & $\begin{array}{l}53 \\
47\end{array}$ \\
\hline $\begin{array}{l}\text { Spraying pesticides } \\
\text { - No } \\
\text { - Yes }\end{array}$ & $\begin{array}{c}2 \\
48\end{array}$ & $\begin{array}{c}4 \\
96\end{array}$ & $\begin{array}{l}14 \\
36\end{array}$ & $\begin{array}{l}28 \\
72\end{array}$ & $\begin{array}{l}16 \\
84\end{array}$ & $\begin{array}{l}16 \\
84\end{array}$ \\
\hline
\end{tabular}

Ninety six and $72 \%$ of mothers in the two groups of case and control, respectively, reported their cooperation in spraying activities in pistachio farms (table2). Odds ratio calculation showed an increasing risk of spontaneous abortion among those who helped with spraying pesticides in pistachio farms compared to those mothers who did not $(\mathrm{OR}=$ 9.3, 95\% CI = 2.0-43.7) (table 3).

Table 3: The level of risk for experiencing spontaneous abortion among mothers who were facing with some conditions in which their exposure to pesticides increased

\begin{tabular}{lccc}
\multicolumn{1}{c}{ Categories } & \multirow{2}{*}{ The level of risk } & \multicolumn{2}{c}{ 95\% Confidence Interval } \\
\cline { 4 - 4 } & & Lower bond & Upper bond \\
\hline Living place During pregnancy & 1.0 & - & - \\
- Outside pistachio farms & 6.7 & 1.1 & 57.7 \\
- Inside pistachio farms & & & - \\
History of abortion in family & 1.0 & - & 2.6 \\
- No & 2.1 & 1.7 & - \\
- Yes & & & 22.6 \\
Farming (working in pistachio farms) & 1.0 & - & - \\
- No & 9.1 & 3.7 & - \\
- Yes & & & - \\
Spraying pesticides & 1.0 & 2.0 & 43.7 \\
- No & 9.3 & & \\
- Yes & & & \\
\hline
\end{tabular}

\section{Discussion}

Our results showed that the two groups of mothers with and without spontaneous abortion were properly matched. There were not any significant differences between the two groups of case and control based on the number of pregnancy, social class, the place of living, family job, educational status, the exposure to trauma and X-ray during pregnancy and smoking. This shows that the effect of these factors on the independent factor (spontaneous abortion) was adequately controlled. This increases the strength of the causal relation between the independent variable (exposure to pesticides) and 
dependent variable (spontaneous abortion) obtained in our study.

There were few variables measured in our study representing the history of exposure to pistachio farm pesticides. These include living place of respondents during pregnancy (inside or outside the pistachio farms), the distance between living place of respondents during pregnancy and pistachio farms (close or far from pistachio farms), working in pistachio farms during pregnancy as well as respondent's cooperation in spraying pesticides in pistachio farms.

Our findings showed that significantly higher proportions of mothers with spontaneous abortion were living inside pistachio farms during their pregnancy compared to mothers who had not abortion. Further, mothers with spontaneous abortion were, significantly, closer to the pistachio farms during their pregnancy in comparison with mothers with no abortion. Also, a very big majority of mothers with spontaneous abortion (case group) had the experience of working in pistachio farms as well as helping with spraying pesticides in pistachio farms during their pregnancy $(72 \%$ and $96 \%$, respectively). Whereas, these proportions were significantly lower among mothers in the control group (22\% and $72 \%$, respectively). The risk level of experiencing spontaneous abortion among mothers who were facing with these variables was significantly higher than this risk among mothers who did not face these variables. The common point between these variables is that respondents could have direct contact to pesticides based on these variables. No protective equipment is usually used over the duration of working in pistachio farms by pistachio farmers. We concluded that mothers who had direct contact to pesticides (due to living inside or close to pistachio farms and/or working in pistachio farms and/or cooperation in spraying pesticides in pistachio farms during the pregnancy), had significantly higher level of risk for experiencing spontaneous abortion compared to mothers who did not have this contact.
Exposure to poisons such as pesticides can be intentional or unintentional and the effects vary with the amount of exposure. Similar to the community of our study, there are many reports of poisoning by pesticides worldwide [21]. Unintentional exposure to pesticides among respondents in our study is due to their occupational affairs. Pesticides exposure generates both acute and chronic disadvantages of which spontaneous abortion is very important. The effect of exposure to pesticides on human health is widely measured [22]. Beseler et al concluded that both acute high-intensity and cumulative pesticide exposure may contribute to depression in pesticide applicators [23]. The disadvantages of exposure to pesticides have been known for several decades. For example, the Minamata episode in the 1950's in Japan has made it clear that pregnant women who are exposed to low concentrations of pesticides (e.g methimercury) may experience few symptoms and yet can give birth to severely retarded children [24]. Exposure to high concentration of these chemical substances is even more dangerous and is happening among pistachio farmers in the area of this study at the moment. It has been claimed that genetic differences may have a great effect on toxicity [25]. In our study we measured the history of spontaneous abortion among the family of the two groups of case and control. Our results confirmed that this history in mothers with spontaneous abortion was more frequently reported compared to the other group who did not have spontaneous abortion. This result could confirm the effect of genetic factors on abortion. However, this might be due to similar job and similar exposure to pistachio pesticides due to their family occupation e.g. working in pistachio farms.

Pesticides are classified based on their chemical structures which include organochlorides such as DDT and endosulfan, organophosphorus such as diazinon, carbamates such as fenoxycarb, pyrethroids such as fenvalerate, anilides/anilines such as metolachlor, phenoxy such as fenoprop 
triazines such as atrazine and propazine, quaternary such as paraquat ureas such as metsulfuron. Most of these chemical substances have been used in pistachio farms. The method of exposing to pesticides in our study is a direct contact to sprayed diluted pesticide into air which is entered into respiratory system of respondents' body. However, it has been reported that dermal absorption is also suspected to be the main source of occupational exposure [26]. Further to our investigation, some studies found significant high risk of spontaneous abortion among women directly exposed to pesticides [27-31]. However, a typical case of poisoning by cutaneous absorption, will also, develop headache, confusion, anorexia and a sense of unreality. It has been reported that over 700 active ingredients are in use worldwide as pesticides, each with specific chemical and toxicological properties [26].

It should be declared again that in addition to the desired effects of crop protection, pesticides have also shown some adverse impacts on both human health and the environment. Humans are at great risk of exposure through several pathways in occupational, agricultural and household use. There are four possible routes for pesticide exposure including inhalation, oral, dermal and ocular exposures. Ingestion of food and water is thought to be the main routes of pesticide exposure in the general population. Pesticides may cause reproductive toxicity with direct damage to the structure of the cells or as a result of biotransformation into metabolites, or interference with processes necessary for the natural homeostasis and equilibrium.

\section{Conclusion}

It is concluded from our findings that exposure to pesticides has been a great risk for causing spontaneous abortion among pregnant female pistachio farmers in the area of this research. Since there are many other disadvantages of exposure to pesticides which are being used in very high amounts in pistachio farms in Kerman province (in particular in Rafsanjan), Southeast, IR. Iran, this problem must be listed as one of the highest health concerns of local health headquarters. Further investigations are also recommended.

\section{Acknowledgment}

We thank all respondents who agreed to help with this work. We also appreciate the valuable help we have received from general practitioners in recruiting respondents and data collection process.

Conflict of interest: Non declared

\section{References}

1. Ramazzini C. Collegium ramazzini statement on the control of pesticides in the European Union: A call for action to protect human health. Am J Ind Med 2009; 52(2):176-7.

2. Food and Agriculture Organization of the United Nations. International code of conduct on the distribution and use of pesticides. Rev. Ver. Rome, Italy: Food and Agriculture Organization of the United Nations; 2003.

3. Jeyaratnam J. Acute pesticide poisoning: a major global health problem. World Health Stat Q 1990; 43(3):139-44.

4. Sanborn M, Kerr KJ, Sanin LH, Cole DC, Bassil KL, Vakil C. Non-cancer health effects of pesticides: systematic review and implications for family doctors. Can Fam Physician 2007; 53(10):1712-20.

5. Alavanja MC, Hoppin JA, Kamel F. Health effects of chronic pesticide exposure: cancer and neurotoxicity. Annu Rev Public Health 2004; 25:155-97.

6. Ritter L, Goushleff NC, Arbuckle T, Cole D, Raizenne M. Addressing the linkage between exposure to pesticides and human health effectsresearch trends and priorities for research. $\mathrm{J}$ Toxicol Environ Health B Crit Rev 2006; 9(6):441-56.

7. McCauley LA, Anger WK, Keifer M, Langley R, Robson MG, Rohlman D. Studying health outcomes in farmworker populations exposed to pesticides. Environ Health Perspect. 2006; 114(6):953-60. 
8. Bassil KL, Vakil C, Sanborn M, Cole DC, Kaur JS, Kerr KJ. Cancer health effects of pesticides: systematic review. Can Fam Physician 2007; 53(10):1704-11.

9. García AM. Pesticide exposure and women's health. Am J Ind Med 2003; 44(6):584-94.

10. Weselak M, Arbuckle TE, Foster W. Pesticide exposures and developmental outcomes: The epidemiological evidence. J Toxicol Environ Health B Crit Rev 2007; 10(1-2):41-80.

11. Peiris-John RJ, Wickremasinghe R. Impact of low-level exposure to organophosphates on human reproduction and survival. Trans $\mathrm{R}$ Soc Trop Med Hyg 2008; 102(3):239-45.

12. Kajii T, Kida M, Takahashi K. The effect of thalidomide intake during 113 human pregnancies. Teratology 1973; 8(2):163-6.

13. De Roos AJ, Stewart PA, Linet MS, Heineman $\mathrm{EF}$, Dosemeci M, Wilcosky $\mathrm{T} \&$ et.al. Occupation and the risk of adult glioma in the United States. Cancer Causes Control 2003; 14(2):139-50.

14. Rajaraman P, De Roos AJ, Stewart PA, Linet MS, Fine HA, Shapiro WR \& et.al. Occupation and risk of meningioma and acoustic neuroma in the United States. Am J Ind Med 2004; 45(5):395-407.

15. Carreón T, Butler MA, Ruder AM, Waters MA, Davis-King KE, Calvert GM \& et.al. Gliomas and farm pesticide exposure in women: the Upper Midwest Health Study. Environ Health Perspect 2005; 113(5):546-51.

16. Khuder SA, Mutgi AB, Schaub EA. Metaanalyses of brain cancer and farming. Am J Ind Med 1998; 34(3):252-60.

17. Frazier LM. Reproductive disorders associated with pesticide exposure. J Agromedicine 2007; 12(1):27-37.

18. Inskip PD, Linet MS, Heineman EF. Etiology of brain tumors in adults. Epidemiol Rev 1995; 17(2):382-414.

19. Muslcco M, Sant M, Molinari S, Filippini G, Gatta G, Berrino F. A case-control study of brain gliomas and occupational exposure to chemical carcinogens: the risk to farmers. Am J epidemiol 1988; 128(4):778-85.

20. Preussmann R, Eisenbrand G (1984). N-Nitroso carcinogens in the environment. In: Searle CE, ed. Chemical carcinogens. Washington, DC: American Chemical Society. P829-68.

21. Lee SJ, Mehler L, Beckman J, Diebolt-Brown B, Prado J, Lackovic M \& et.al. Acute pesticide illnesses associated with off-target pesticide drift from agricultural applications: 11 States, 19982006. Environ Health Perspect 2011; 119(8):1162-9.

22. Calvert GM, Sanderson WT, Barnett M, Blondell JM, Mehler LN (2001). Surveillance of pesticide-related illness and injury in humans. In: Krieger R, ed. Handbook of pesticide toxicology. $2^{\text {nd }}$ ed. San Diego, CA: Academic Press. P603-41.

23. Beseler CL, Stallones L, Hoppin JA, Alavanja MC, Blair A, Keefe T \& et.al. Depression and pesticide exposures among private pesticide applicators enrolled in the Agricultural Health Study. Environ Health Perspect 2008; 116(12):1713-9.

24. Turney WG. Mercury pollution: Michigan's action program. J Water Pollut Control Fed 1971; 43(7):1427-38.

25. Tsatsakis AM, Zafiropoulos A, Tzatzarakis MN, Tzanakakis GN, Kafatos A. Relation of PON1 and CYP1A1 genetic polymorphisms to clinical findings in a cross-sectional study of a Greek rural population professionally exposed to pesticides. Toxicol lett 2009; 186(1):66-72.

26. Toppari J, Larsen JC, Christiansen P, Giwercman A, Grandjean P, Guillette LJ Jr \& et.al. Male reproductive health and environmental xenoestrogens. Environ Health Perspect 1996; 104(Suppl 4):741-803.

27. Arbuckle TE, Savitz DA, Mery LS, Curtis KM. Exposure to phenoxy herbicides and the risk of spontaneous abortion. Epidemiology 1999; 10(6):752-60.

28. Arbuckle TE, Lin Z, Mery LS. An exploratory analysis of the effect of pesticide exposure on the risk of spontaneous abortion in an Ontario farm population. Environ Health Perspect 2001; 109(8):851-7.

29. Nurminen T. Maternal pesticide exposure and pregnancy outcome. J Occup Environ Med 1995; 37(8):935-40.

30. Petrelli G, Figà-Talamanca I, Tropeano R, Tangucci M, Cini C, Aquilani S \& et.al. Reproductive male-mediated risk: spontaneous abortion among wives of pesticide applicators. Eur J Epidemiol 2000; 16(4):391-3.

31. Crisostomo L, Molina VV. Pregnancy outcomes among farming households of Nueva Ecija with conventional pesticide use versus integrated pest management. Int J Occup Environ Health 2002; 8(3):232-42. 